\title{
The Major Developments of the Evolving Reverse Osmosis Membranes and Ultrafiltration Membranes
}

\author{
M. Kurihara and Y. Himeshima \\ Membrane Laboratory, Toray Industries, Inc., \\ Otsu, Shiga 520, Japan
}

(Received November 29, 1990)

\begin{abstract}
The current status of reverse osmosis and ultrafiltration membranes are reviewed with the view for the future. In the case of reverse osmosis (R0) membranes, as examples, new crosslinked aromatic polyamide membranes exhibited the superior separation performance with the sufficient water permeability, the high tolerance for oxidizing agents and chemicals. Ultrafiltration (UF) membrane based on poly(phenylene sulfide sulfone)(PPSS) also exibited the superior separation performance with, the high solvent, heat and fouling resistance.
\end{abstract}

KEY WORDS
$\begin{aligned} & \text { Membrane Reverse Osmosis Membrane / Ultrafiltration } \\ & \text { sulfide sulfone)(PPSS) }\end{aligned}$

Reverse osmosis and ultrafiltration membranes have gotten a major position in the industrial separation technology. Despite of the progress and the increasing adoption of these membranes, there remain significant limitation to broder utilization.

In the case of reverse osmosis, new membranes were required to have superior performance, which are presented as 1) high selectivity 2) high water permeability 3) tolerance for oxidizing agents. High selectivity is the strong demand in an ultrapure water production and a saline water desalination. High water permeability is necessary for low pressure and low running cost operation. And tolerance for oxidizing agents allows to operate the system dependably without biological fouling.

In the case of ultrafiltration, membranes which are made of polysulfone, polyacrylonitrile, cellulose acetate derivatives, polyimides have been used in such a processes for the recovery of electrocoat painting and cheese whey and the production of pyrogen free water and ultrapure water. New membranes are required to have superior performance, which are represented as 1) sharpness of molecure weight cutoff 2) solvent and high temperature resistance 3 ) fouling resistance (low nonspecific solute adsorption).

Reverse Osmosis (R0) membranes

Numerouse researches have been done for membrane materials, structure and fabrication technology to exceed asymmetric 
cellulose acetate and aromatic polyamide membranes. In-situ interfacial polycondensation method was developed to obtain the high performance composite membrane. Crosslinked polyamide composite membranes, which overcome these problems have been commercialized and become one of the major reverse osmosis membrane today.

Membrane Materials in the Market

Dr. Petersen of FilmTec /Dow has classified membrane materials in the market ${ }^{1}$. Table I shows his classification together with additional remarks by Toray. Looking at the membrane materials/membrane morphology /element configuration, all the low pressure membrane belong to spiral wound elements with crosslinked polyamide/polyurea composite membrane. As table I shows, crosslinked polyamide /polyurea composite membrane materials are roughly separated into crosslinked fully aromatic polyamide (I), crosslinked aryl-alkyl polyamide/polyurea(II), and crosslinked polypiperazineamide (III) .

\section{Crosslinked Fully Aromatic} Polyamide (I)

DuPont's B-9 and B-10

Table 1. Classification of Commercial Reverse 0smosis Membranes

\begin{tabular}{|c|c|c|}
\hline Membrane Material/Maker & Trade Name & Element Configuration \\
\hline $\begin{array}{l}\text { Crosslinked Fully Aromatic Pol } \\
\text { FilmToc } \\
\text { (DDS) } \\
\text { (PCI) } \\
\text { Toray } \\
\text { Nitto Denko }\end{array}$ & $\begin{array}{l}\text { yamide } \\
\text { TW/Bw/SW/HR-30* } \\
\text { HR-95t. HR-99z } \\
\text { ZF-99* } \\
\text { SU-700*t, SU-800*t, } \\
\text { SU-900*t. } \\
\text { NTR-759* }\end{array}$ & $\begin{array}{l}\text { spiral } \\
\text { plate } 8 \text { frame } \\
\text { tubular } \\
\text { spirai } \\
\text { spiral }\end{array}$ \\
\hline $\begin{array}{l}\text { Linear Fully Aromatic Polyamic } \\
\text { DuPont } \\
\text { DuPont }\end{array}$ & $\begin{array}{l}\text { Permasop B-9. } B-10 \\
\text { Pormasep B-15 }\end{array}$ & $\begin{array}{l}\text { hollow fine fiber } \\
\text { spiral }\end{array}$ \\
\hline $\begin{array}{l}\text { Aryl-A|ky| Polyamide/Polyurea } \\
\text { UOP } \\
\text { Hydransutics } \\
\text { Nitto Denko } \\
\text { DuPont }\end{array}$ & $\begin{array}{l}\text { RC- } 100 \text { (and PA-300)* } \\
\text { CPA* } \\
\text { NTR-7197* NTR-739HF* } \\
\text { Pormasep A-15* }\end{array}$ & $\begin{array}{l}\text { spiral } \\
\text { spiral } \\
\text { spiral } \\
\text { spiral }\end{array}$ \\
\hline $\begin{array}{l}\frac{\text { Polypiperazineamides }}{\text { FilmTec }} \\
\text { Nitto Denko } \\
\text { Toray }\end{array}$ & $\begin{array}{l}\text { NF-40*. NF-40HF* } \\
\text { NTR-7250*. NTR-729HF* } \\
\text { SU-200*+. SU-600*+ } \\
\text { SU-500*t. }\end{array}$ & $\begin{array}{l}\text { spiral } \\
\text { spiral } \\
\text { spiral }\end{array}$ \\
\hline $\begin{array}{l}\text { Cellulose Acetate } \\
\text { Torgy } \\
\text { UOP } \\
\text { Hydranautics } \\
\text { DSI } \\
\text { DuPont }\end{array}$ & $\begin{array}{l}\text { SC-1000.3000 } \\
\text { ROGA-4160 } \\
400 B-1620 C A \\
8054-98 \\
C-1\end{array}$ & $\begin{array}{l}\text { spiral } \\
\text { spiral } \\
\text { spiral } \\
\text { spiral } \\
\text { spiral }\end{array}$ \\
\hline$\frac{\text { Collulose Triacetate }}{\text { Toyobo }}$ & Hollosep & hollow fiber \\
\hline$\frac{\text { Crosslinked Polyether }}{\text { Toray }}$ & PEC-1000* & spiral \\
\hline$\frac{\text { Polyacrylonitrite }}{\text { Sumitomo }}$ & Solrox & tubular, spiral \\
\hline$\frac{\text { Polybenzimidazolone }}{\text { Teijin }}$ & PBIL & tubular, spiral \\
\hline $\begin{array}{l}\text { Sul fonated Polysulfone } \\
\text { DSI } \\
\text { Millipore } \\
\text { Nitto Denko }\end{array}$ & $\begin{array}{l}\text { Desal Plus: } \\
\text { PSR0* } \\
\text { NTR-7410.7450* }\end{array}$ & $\begin{array}{l}\text { spiral } \\
\text { spiral } \\
\text { spiral }\end{array}$ \\
\hline
\end{tabular}

composite membrane. are well known as membranes

with linear fully aromatic polyamide ${ }^{2}$. Their hollow fine fiber membrane module is particularly and widely employed for seawater desalination mainly in Middle East. DuPont has launched B-15, a spiral wound element with asymmetric membrane. These membrane materials are all linear aromatic polyamide, and sulfonate groups linked with the side chain makes them different from the materials of the below mentioned composite membranes. FilmTec's $\mathrm{TW} / \mathrm{BW} / \mathrm{SW} / \mathrm{HR}-30^{3}$, DDS's and PCI's membranes are all in composite membrane morphology, which consist of crosslinked aromatic polyamide with carboxylate groups. Toray's UTC-70 membrane (SUseries elements are made of UTC- series membranes) based on $1,3,5$-triaminobenzene also belongs to the same group ${ }^{4}$. Fig.1 shows a typical chemical structure of the ultra thin film layer of the crosslinked fully aromatic polyamide composite membrane ${ }^{5}$.

Crosslinked Aryl-Alkyl Polyamide/Polyurea (II)

In the market, the reverse osmosis membranes belonging to this category are all composite membranes in spiral wound configuration. Compared with the crosslinked fully aromatic 
polyamide, basic membrane performance are almost same, while resistance to oxidizing agents is rather low.

DuPont introduced polyamide membrane consisting of $\mathrm{m}$-phenylenediamine/cyclohexane tricarboxylic acid condensate, which is said to have high flux and may be related to their A-15 membrane.

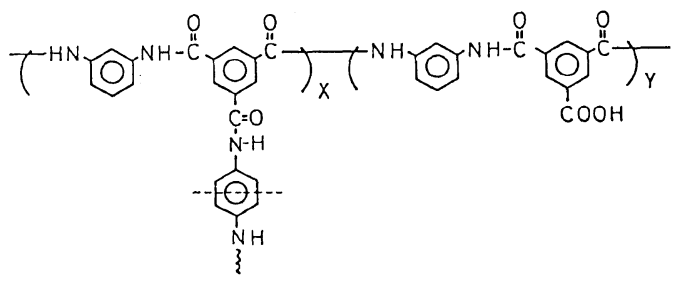

Fig. 1

Chemical Structure of the

Crosslinked Fully Aromatic Polyamide ${ }^{5}$

Crosslinked Polypiperazineamide(III)

Polypiperazineamide
was first introduced by
Montedison as a linear
polypiperadineamide mem-
brane with chlorine
tolerant property (not
listed in Table I), but was finally not commercialized since it did not show clear performance merit in comparison with CA membrane. However, Toray's UTC-60 membrane, which was commerciarized several years ago belongs to this kind of category. The membranes in Table I

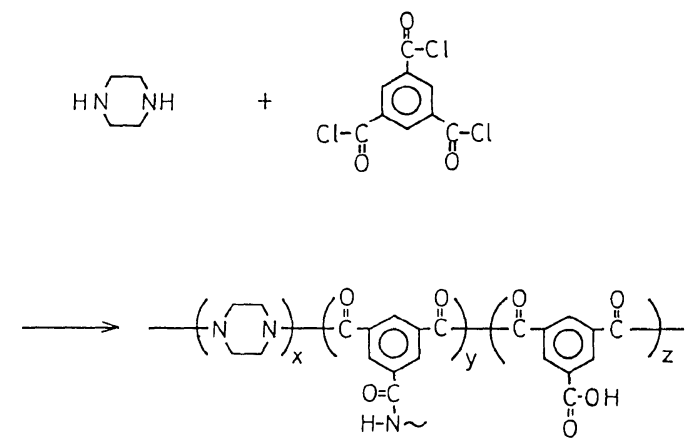

Fig. 2

Chemical Structure of Crosslinked Polypiperadineamide ${ }^{1}$ are all composite membranes which consist of crosslinked polypiperazineamide. This kind of membrane is categorized as a loose RO, which has feature of 1) high water flux and 2) chlorine tolerance. A typical chemical structure of the crosslinked polypiperazineamide is shown in Fig. $2^{1}$.

New Reverse Osmosis Membranes

In ICOM'90, membrane makers introduced various new membranes. Toray's new UTC-70\&UTC-80 series and UTC-90 belong to the aforementioned crosslinked fully aromatic polyamide membrane group. Nitto/Hydranautics introduced NTR-759UP, which focus on the high total organic contamination (TOC) rejection. TOYOBO have also presented the new aromatic linear polyamide membrane, which was designed and developed for the increase of chlorine resistance. This membrane has an electron withdrawing group $\left(-\mathrm{SO}_{2}-\right)$, which is effective to suppress chlorine adsorption.

Performance of Reverse Osmosis Membranes

Categolized the reverse osmosis membranes by their operating pressure, they were divided into high pressure membrane (more than $40 \mathrm{~kg} / \mathrm{cm}^{2}$ ), middle pressure membrane (20-40 $\left.\mathrm{kg} / \mathrm{cm}^{2}\right)$, low pressure membrane $\left(10-20 \mathrm{~kg} / \mathrm{cm}^{2}\right)$ and very low pressure membrane (less than $10 \mathrm{~kg} / \mathrm{cm}^{2}$ ). Lineup of Toray's reverse osmosis membranes and separation performance were shown in Fig. 3. It can been seen that Toray's membranes showed the 
superior separation performance.

Low Pressure Reverse 0smosis Membranes

Reverse osmosis membrane can practically reject not only suspended solids such as paticulates or colloids but also almost all dissolved compounds such as ions or organic substances except gases. Reverse osmosis membrane process has been already widely accepted as one of indispensable fundamental techniques because it is the most suitable separation techniques for ultrapure water production from raw water such as municipal water or well water, which requires theoretical pure water without limit. Accumulation of Large Scale Integration(LSI) has been rapidly progressed, which lead strict requirements to ultrapure water.

UTC-70 series membranes are now widely employed as the pretreatment of ion exchnge process. UTC-70R membrane can be used in the water recovery from waste water treatment system. In this case, the rejection of low molecular weight total organic contamination (TOC) is very impotant. Table II shows that UTC70R membrane gives remarkably high rejection to all of neutral, acidic or alkalic organics, and especially to isopropyl alcohol, which is considered as a standard substance to measure TOC removal property.

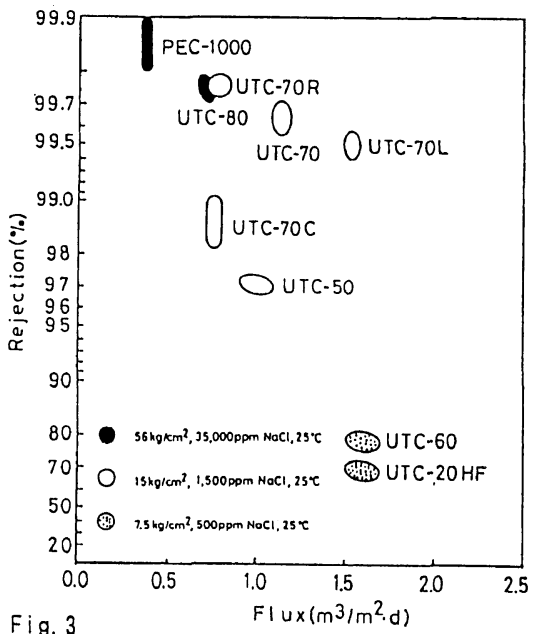

Desalination Performance of RO Membarnes at Various Operating Pressures

Table II. Organic Rejection ofUTC-70R Membrane

\begin{tabular}{|l|c|c|}
\hline \multicolumn{1}{|c|}{ Solutes } & MW & Rejection $(x)$ \\
\hline Methanol & 32.04 & 13.1 \\
Ethanol & 46.07 & 60.9 \\
Isopropanol & 60.10 & 98.1 \\
Urea & 60.06 & 68.8 \\
Acotic Acid & 60.05 & 58.1 \\
Ethylene Glycol & 64.09 & 84.7 \\
I-Caprolactam & 113.16 & $>99.2$ \\
\hline
\end{tabular}

Feed Conc. 1000 ppm, Press. $15 \mathrm{~kg} / \mathrm{cm}^{2}$. Temp. $25^{\circ} \mathrm{C}$ Another
application of
UTC-70 series is
the substitution
of the ion exchange process, so-called "two stage RO process", which omits ion exchngetowers using regeneration type resins. As shown in Fig. 4, UTC-90 membrane, which had an excellent
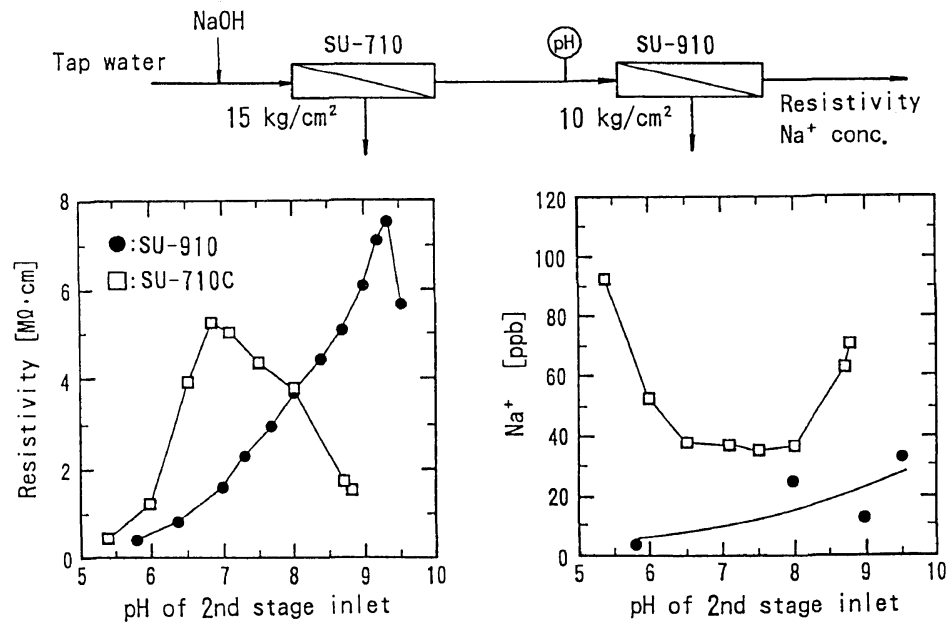

Fig. 4 pH Dependence of Resistivity in Two Stage RO Process 
resistivity and rejection of sodium ion in an alkali region is expected to applied for "two stage RO process".

Another application of UTCseries is also the posttreatment of ion exchange resins so-called cartridge polisher. UTC-70C membrane, which has high rejection in the lower range of solute concentration, are expected in posttreatment of ion exchange process. Fig. 5 shows the rejection performance for trimethylamine,

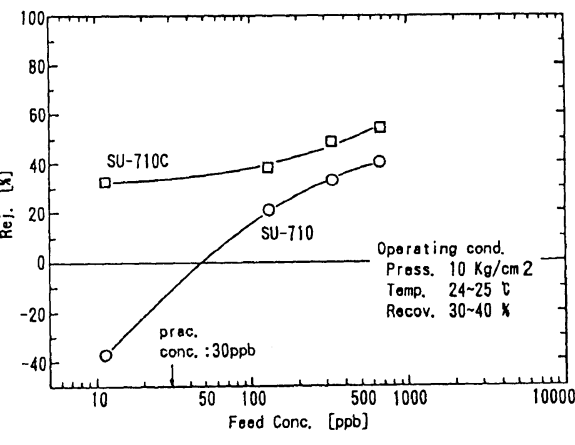

Fig. 5 Rejection of Trimethylamine which is considered to be one of the eluted components from the ion exchange resins. UTC-70C has the good rejection, thus it can be used in the posttreatment of the ion exchange resins.

Tolerance for Oxidizing Agents of UTC-7.0 Membrane

The durability of membrane against oxidizing agents such as chlorine and hydrogen peroxide is an impotant point in an actual application. Table II shows the chlorine tolerance of UTC-70 membrane. After exposure to $100 \mathrm{ppm}$ chlorine for 50 hours, the decline of sodium chloride rejection was within the allowable range. However, in the presence of heavy metal ion, oxidative membrane degradation was accerated. Especially, manganese (II) ion can react with sodium hypochlorite in the presence of copper and generate permanganate ion,

which is a strong oxidant 6 . In this system, membrane performance was fallen to the low level during a short time.

Table IV shows the durability against hydrogen peroxide. UTC-70 membrane has the high tolerance for hygrogen peroxide. In this test, EDTA is dosed to prevent hydroxy radical formation. Hydroxy radical is a strong oxidizing agent, which emerges in the presence of ferric ion.

\section{Very Low Pressure Reverse Osmosis Membrane}

This kind of membranes are called "loose RO" and operated less than $10 \mathrm{~kg} / \mathrm{cm}^{2}$. From view point of membrane material, the membranes are divided into two categories, crosslinked fully aromatic polyamide $(\mathrm{NF}-50, \mathrm{NF}-70)$, and polypiperazineamide (UTC-20HF, UTC-60, NTR-7250, NF-40, NF-40HF). Separation 
performance of these membranes at $7.5 \mathrm{~kg} / \mathrm{cm}^{2}$ were shown in Fig. 6 .

Hereafter the features of UTC-60 and UTC-20HF will be introduced as examples.

As reverse osmosis membrane, these membranes did not give a high rejection of low molecular weight organics. However, UTC-60 when the objective organics was acidic, or UTC-20HF when the objective organics was basic, worked rather better. Moreover, organics lager than cane sugar (Mw 342.3) were almost perfectly rejected which opened the way to application in food industries.

Tolerance for 0xidizing Agents of UTC-60 Membrane

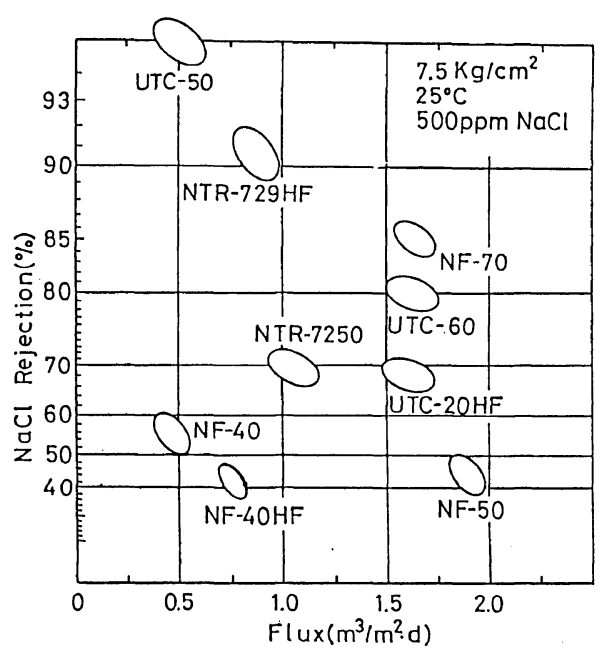

Fig. 6

Comparison of Desalination Performance of Commercially Available UItra Low Pressure Membranes

$\begin{array}{lll}\text { Table } V & \text { gives the test } \\ \text { results of } & \text { UTC- } 60 & \text { under }\end{array}$ continuous dosing of 10-100ppm of chlorine. The membrane performance after about 13,000 ppm hr. exposure declined from $82 \%$ initial rejection down to $80 \%$, and $1.4 \mathrm{~m}^{3} / \mathrm{m}^{2}$ day initial flux down to $1.13 \mathrm{~m}^{3} / \mathrm{m}^{2}$ day with level of

Table V. Chlorine Tolerance of UTC-60 Membrane

\begin{tabular}{ccc} 
& \multicolumn{2}{c}{ Chlorine Expos. } \\
$\mathrm{Cl}_{2}$ Conc. (ppm-hrs) & Rejection( $(x)$ \\
\hline I & $0-24$ & 82.0 \\
II & $10-100$ & 85.0 \\
III & $50-115$ & 89.5 \\
IV & $100-130$ & 80.0 \\
\hline \multicolumn{3}{r}{ Press. $7.5 \mathrm{~kg} / \mathrm{cm}^{2}, \mathrm{NaCl} 500 \mathrm{ppm}, \mathrm{pH} 6.5,25^{\circ} \mathrm{C}$}
\end{tabular}

performance change suggested that the chlorine tolerance of UTC- 60 was at the level of CA membrane.

\section{Ultrafiltration (UF) Membranes}

Since A.S.Michaels sucessed to make an artificial ultrafiltration membrane, various kinds of membranes has been investigated and developed.

Recentry, there is an increasing need for separation of proteins and peptide drugs from biological broths due to the development of biotechnology. However, many ultrafiltration membranes have been troubled with membrane fouling, which changes membrane performance during operation. In the pharmaceutical and the food industry, ultrafiltration membrane is required to have a high temperature resistance and a solvent resistance, which can allow to use in nonaqueous system.

Membrane Materials of UF Membrane

In order to satisfy these requirements, many types of UF membranes were tested in the aforementioned fields.

Cellulose acetate (CA) membrane has high water permeability and easy manufacturing as an advantage. However, a fairly narrow temperature range, a rather narrow $\mathrm{pH}$ range, compaction and biodegradation limit to expand its applied field. 
Polyacrylonitrile (PAN) membranes are widely used. However, this membrane sometimes trouble with fouling by nonspecific adsorption.

At the present day, polysulfone is one of the most popular membrane material because of its high durability. Advantages of this membrane are wide temperature limit, wide $\mathrm{pH}$ tolerance, fairly good chlorine resistance and availability of wide range pore size. However, this membrane also could not avoid a membrane fouling. Numerous investigations have been done to overcome this problem. In general, it is practically said that a hydrophilic material is preferable as a fouling resistance membrane material.

First approach of hydrophilic polysulfone membrane is coating of hydrophilic material on the membrane surface ${ }^{7}$ and next one is introduction of hydrophilic group, such as sulfonate, carboxylate, 8 amino and hydroxyl group, to a polysulfone's main chain ${ }^{8}$. As an another approach, blend or graft of 9 polyvinylpyrrolidone (PVP) derivertive was investigated 9 . In spite of these reserchs, ultrafiltration membrane, which has a fouling resistance with a high durability has not yet developed.

UF Membranes based on PPSS

PPSS is an amorphous super engineering plastics, which has a high glass transition temperature $\left(215{ }^{\circ} \mathrm{C}\right)$, more hydrophilic than polysulfone and solvent resistance. Chemical structure is shown in Fig.7. We have found that asymmetric PPSS UF membrane could be fabricated by using a phase inversion method. Fig. 8 shows the separation performance of PPSS flat membrane (PPSS-I). Separation performance can be easily controlled by fabrication condition. Molecular weight cutoff level was among 40,000 - 100,000 with the high water permiability comparison with polysulfone membranes.

We have also found another incredible phenomenon. Oxidative treatment of PPSS-I UF membrane could give the more heat and solvent resistance, and the more hydrophilicity without change of membrane separation performance. These phenomena is presumed results of improving the crystallinity of the polymer and increasing the amount of hydrophilic $-\mathrm{SO}_{2}-$ linkage.

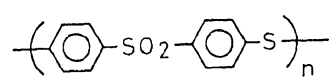

Fig. 7 Chemical Structure of Poly (phenylene sulfide sulfone)

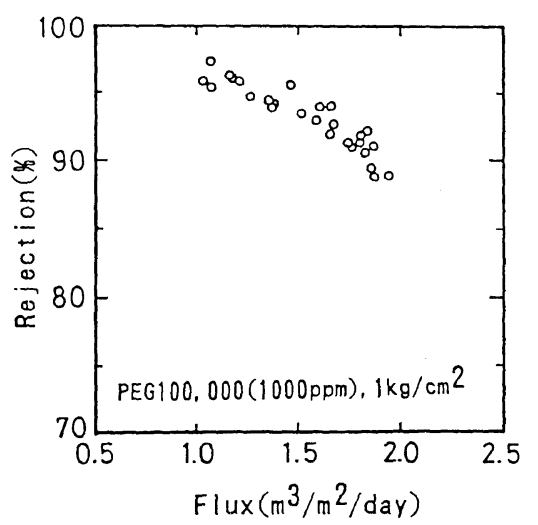

Fig. 8

Separation Performance of PPSS UF Membranes

Fig.9 shows the retention rate of separation performance after immersed in organic solvents for 50 hours. It is clear that the PPSS-I and the oxidized PPSS membrane (designated as PPSS-II) has an excellent solvent resistance. Fig.10 shows the retention rate of separation performance after autoclave 
treatment at $121^{\circ} \mathrm{C}$. Although, heat resistance of PPSS membrane was the same as polysulfone membrane's one, the PPSO membrane was very high. Fig.11 shows preliminary results of fouling resistance by using bovine serum albumin(BSA) as a fouling material. PPSS \& PPSO membrane have an excellent fouling resistance.

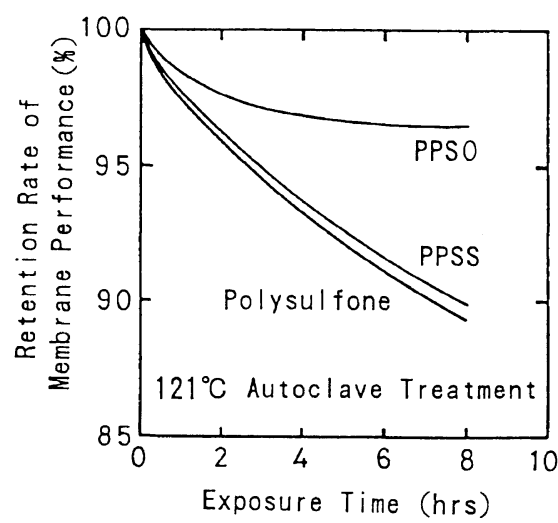

Fig. 10

Heat Resistance of PPSS and PPSO Membrane

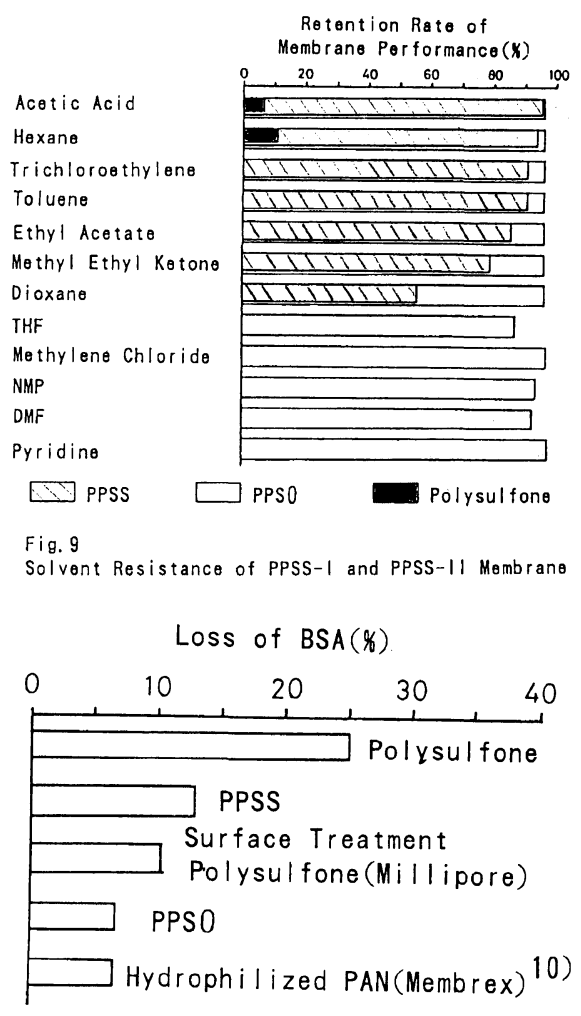

Fig. 11 Fouling Resistance of UF Membrane 20 fold diluted BSA (pH7. 5)

\section{REFERENCES}

1.R.J.Petersen, presented at the 1st Biennial Conference of the National Water Supply Improvement Association, Washington D.C. June 8-12,1986.

2.J.W.Richter and H.H.Hoehn, U.S.Patent 3,567,632(1971).

3.J.E.Cadotte, U.S.Patent 4,277, 344(1981).

4.M.Kurihara, Y.Himeshima and T.Uemura, presented at the 1990 International Congress on Membrane and Membrane Processes, Chicago, Aug. 19-25, 1990 .

5.J.Koo, R.J.Petersen and J.E.Cadotte, ACS Polym.Prepr.,27, 391 (1986) .

6.M.W.Lister, Canadian J. Chem., 34,479(1955).

7.A.S.Michaels, C.R.Robertson and H.Reihanian, presented at the 1987 International Congress on Membrane and Membrane Processes, Tokyo, June 8-12,1987.

8.S.Nakao, H.Osada, H.Kurata and S.Kimura, Desalination, 70,191 (1988).

9.Daisel, Japan Patent (Tokkai) 62-201603 (1987) .

10.Leonard, T.Hodgins, PCT International Appl. 88/05688(1988) . 